\title{
Pesticides and passive dispersal: acaricide- and starvation-induced take-off of the predatory mite Neoseiulus baraki
}

\author{
Vaneska Barbosa Monteiro, ${ }^{\mathrm{a}^{*}}$. Vanessa Farias Silva, ${ }^{\mathrm{a}}$ Debora Barbosa Lima, ${ }^{\mathrm{a}}$ \\ Raul Narciso Carvalho Guedes ${ }^{b, c_{\odot}}$ and Manoel Guedes Correa Gondim Jra
}

\begin{abstract}
BACKGROUND: An understanding of the causes and consequences of dispersal is vital for managing populations. Environmental contaminants, such as pesticides, provide potential environmental context-dependent stimuli for dispersal of targeted and non-targeted species, which may occur not only for active but also for passive dispersal, although such a possibility is frequently neglected. Here, we assessed the potential of food deprivation and acaricides to interfere with the take-off for passive (wind) dispersal of the predatory mite Neoseiulus baraki.

RESULTS: Wind tunnel bioassays indicated that starvation favoured the take-off for wind dispersal by the mite predator, which also varied with wind velocity, and dispersal increased at higher velocities within the 1-7 (m s $\mathrm{s}^{-1}$ ) range tested. For the acaricides tested, particularly the biopesticide azadirachtin but also abamectin and fenpyroximate, the rate of predator take-off for dispersal increased, and further increased with wind velocity up to $7 \mathrm{~m} / \mathrm{s}$. Such responses were associated with changes in the predator behavioural preparation for wind-mediated passive dispersal, with a greater incidence of the standing posture that permitted take-off.

CONCLUSION: The rate of take-off for passive dispersal by $\mathbf{N}$. baraki increased with food deprivation and exposure to the residues of agricultural acaricides. Azadirachtin exposure resulted in a particularly strong response, although abamectin and fenpyroximate also stimulated dispersal.

(c) 2018 Society of Chemical Industry
\end{abstract}

Keywords: sublethal exposure; bioinsecticide; wind dispersal; biocontrol agent; phytoseiid; food deprivation

\section{INTRODUCTION}

The dispersal of an organism from one patch to another is a trait with fitness consequences for the dispersing individual, with hierarchical significance particularly for population structure and dynamics. ${ }^{1-3}$ Dispersal has a central role in structuring populations because it allows spatial cohesion of conspecifics, global persistence despite local extinctions, and the tracking of favourable environmental conditions. ${ }^{4}$ Thus, dispersal is important for both population management, particularly for integrated pest management, and response to environmental changes, which also has implications for pest control. ${ }^{1,5}$ Furthermore, competition, inbreeding and environmental stochasticity are driving forces of dispersal, which allows adaptation to ephemerally suitable habitats which are common in agroecosystems. ${ }^{1,4}$

Dispersal may be either active or passive and encompasses all movements of individuals in the three following stages: (i) departure (or emigration), (ii) the vagrant stage, and (iii) settling (or immigration) ${ }^{2,5}$ Regardless, dispersal is determined by the balance between the costs and benefits guiding phenotype-dependent and condition-dependent decisions. ${ }^{4,6}$ Declining habitat suitability is an important trigger of dispersal, including reduction of food sources, and changes in temperature and humidity conditions, among others. ${ }^{7}$ Management tactics also potentially compromise habitat suitability, favouring dispersal from the contaminated habitat, a typical condition-dependent decision, although pesticide use may also shift species dominance and prevailing population phenotypes. ${ }^{8-10}$ Curiously, the potential impact of pesticides on the dispersal of targeted and non-targeted species remains largely unrecognized, with even less recognition of passive dispersal. Whereas active dispersal may be potentially compromised by sublethal insecticide effects, particularly those of neurotoxic pesticides which are more likely to impair neural and/or muscle activity, ${ }^{9,11}$ little is known about the potential effect of pesticides on the passive dispersal of arthropods. Nonetheless, such effects may be significant and may potentially either enhance or

\footnotetext{
* Correspondence to: VB Monteiro, Departamento de Agronomia-Entomologia, Universidade Federal Rural de Pernambuco, Av. Dom Manoel de Medeiros $s / n$, Dois Irmãos, Recife, PE 52171-900, Brazil. E-mail: vaneska_barbosa@hotmail.com

a Departamento de Agronomia - Entomologia, Universidade Federal Rural de Pernambuco, Recife, Brazil

b Departamento de Entomologia, Universidade Federal de Viçosa, Viçosa, Brazil

c USDA-ARS San Joaquin Valley Agricultural Sciences Center, Parlier, CA, USA
} 
impair insecticide efficacy depending on the species and context considered.

Passive dispersal is prevalent among some arthropods. For example, mites are usually constrained to a restricted range of conditions because of rather limited locomotor abilities. However, these organisms use a variety of dispersal tactics for reaching alternative patches of suitable habitats. ${ }^{5}$ Therefore, mites are suitable models in which to explore the potential effect of pesticides on passive dispersal, which is also usually affected by food deprivation. ${ }^{7}$ Wind dispersion is common among mite species, and can be favoured by behaviours and postures that prepare the mite for take-off and dispersal. ${ }^{12,13}$ The lifting of body parts in spider mites (tetranychids), ${ }^{14,15}$ eriophyids, ${ }^{16-19}$ and phytoseiids, ${ }^{20,21}$ and the production of structures such as silk threads that allow ballooning or roping in spider mites ${ }^{14,15,22}$ are behaviours commonly associated with (passive) wind dispersal of mites. Exposure to acaricides can affect these behaviours, which may interfere with take-off.

Pesticides may affect passive dispersal by directly affecting mite physiology as a consequence of the toxic effect of primary or secondary modes of action but may also lead to behavioural avoidance and even indirectly interfere with passive dispersal by affecting the density of conspecifics and/or heterospecifics or other environmental conditions. ${ }^{9}$ Therefore, the strength of the dispersal stimuli and their consequences will vary with the mite species and its guild, whether pest or predator, and the environmental context. A reduction in prey density itself, and consequent food deprivation (or starvation), are habitat characteristics that are also potential consequences of pesticide applications and usually favour dispersal, particularly of phytoseiid mites. ${ }^{23-26}$ The phytoseiid Neoseiulus baraki (Athias-Henriot) is a key predator of the coconut mite Aceria guerreronis Keifer (Acari: Eriophyidae), which is notoriously difficult to control and against which acaricides are frequently required to aid in the management of this bract-hidden pest species. ${ }^{27-30}$ Nonetheless, some of the acaricides used against the coconut mite compromise the survival and/or performance of its phytoseiid predator N. baraki. ${ }^{31-34}$

The wind-mediated passive dispersal of $N$. baraki may also be affected by acaricides used against its prey, including the coconut mite, and so this mite species is useful as a model to test pesticide effects on passive dispersal. The biopesticides abamectin and azadirachtin, in addition to the conventional (specific) acaricide fenpyroximate, are frequently used against the coconut mite in the Neotropics, leading to sublethal exposure of N. baraki. ${ }^{32-35}$ Therefore, we hypothesized that sublethal exposure of the phytoseiid predator to these compounds and starvation may interfere with its passive dispersal via wind. Wind tunnel bioassays were conducted to test whether starvation and wind velocity would affect take-off for dispersal, the primary stage of passive dispersal in this species, and whether the different acaricides would interfere with such dispersal. Because abamectin is a neurotoxic compound that blocks gamma-aminobutyric acid (GABA)-gated receptors in inhibitory synapses, ultimately resulting in paralysis, ${ }^{36}$ sublethal exposure to this actinomycete-derived biopesticide probably impairs mite behaviour and compromises dispersal take-off. Fenpyroximate also probably impairs dispersal take-off because its primary mode of action is inhibition of mitochondrial electron transport, which impairs respiration and therefore the activity of an organism. ${ }^{37,38}$ By contrast, azadirachtin is a growth regulator expected to increase dispersal take-off, because this compound elicits behavioural avoidance in some insect species, 8,39 including in the mite N. baraki. $32,33,35$

\section{MATERIALS AND METHODS \\ 2.1 Mites}

Females and males of the predatory phytoseiid mite $N$. baraki were collected from coconut fruits infested with the coconut mite (A. guerreronis) on Itamaracá Island off the coast of the state of Pernambuco, Brazil $\left(07^{\circ} 46^{\prime} \mathrm{S}, 34^{\circ} 52^{\prime} \mathrm{W}\right)$. The mites were reared on discs of black polyvinyl chloride (PVC; $16 \mathrm{~cm}$ diameter) placed on a 1-cm-thick foam mat lining the bottom of a plastic tray kept wet by daily filling the tray with water. The margin of the PVC discs was surrounded with moist hydrophobic cotton to prevent the escape of mites. One hundred female predatory mites were released on each PVC disc, and were daily provided with epidermal fragments of coconut perianth (ca. $1 \mathrm{~cm}^{3}$ ) containing between 80 and 100 coconut mites (A. guerreronis) at different developmental stages. ${ }^{32,34,35}$ The mites were reared under controlled conditions of $27.0 \pm 0.5^{\circ} \mathrm{C}$ and $75.0 \pm 10.0 \%$ relative humidity $(\mathrm{RH})$, with a $12-\mathrm{h}$ photoperiod; the same conditions were used for all bioassays.

\subsection{Acaricides}

Three acaricides in commercial formulations were used in the bioassays with the predatory mite: abamectin (Vertimec; $18 \mathrm{~g}$ a.i./L; emulsifiable concentrate; Syngenta, São Paulo, SP, Brazil), azadirachtin (Azamax; $1.2 \mathrm{~g}$ a.i./L; emulsifiable concentrate; DVA Agro, Ituverava, SP, Brazil), and fenpyroximate (Ortus; $50 \mathrm{~g}$ a.i./L; suspension concentrate; ArystaLifescience, Salto de Pirapora, SP, Brazil). The acaricides were used at the following single rates corresponding to their respective maximum label rate registered for the coconut mite in Brazil: ${ }^{40} 13.5 \mathrm{mg}$ a.i./L for abamectin, $30.0 \mathrm{mg}$ a.i./L for azadirachtin, and $100 \mathrm{mg}$ a.i./L for fenpyroximate. These label rates were sublethal concentrations for the predatory mite, as previously demonstrated, ${ }^{31,34}$ and no mortality was observed during the bioassays.

\subsection{Wind tunnel}

A wind tunnel for microarthropods was used for the wind take-off bioassays, as previously developed and described by Melo et al. ${ }^{19}$ Briefly, the wind tunnel consisted of a glass tube $(3.5 \mathrm{~cm}$ diameter $\times 10 \mathrm{~cm}$ length) with a free air inlet at one end and a PVC connection to a vacuum pump (A10S/220V; Electrolux, Curitiba, PR, Brazil) at the other end. An insect pin (no. 2; $2 \mathrm{~cm}$ long) was glued inside at $0.5 \mathrm{~cm}$ from the free end of the glass tube, and an epidermal disc of coconut fruit $(0.2 \mathrm{~mm}$ thick and $0.5 \mathrm{~cm}$ diameter) was attached to the pinhead. The epidermal disc was edged with insect glue (Biostop; Biocontrole, Indaiatuba, SP, Brazil) to prevent the mites from crawling away from this dispersal take-off platform. The vacuum pump was connected to an AC/DC variable voltage transformer allowing adjustment of the wind velocity within the wind tunnel, which was measured with a digital thermal anemometer $(0.1 \mathrm{~m} / \mathrm{s}$ precision; model 9515 ; TSI, Shoreview, MN, USA) placed at the free end of the tunnel. The experiment with the wind tunnel was observed under a stereomicroscope in ambient conditions of $27.0 \pm 1.0{ }^{\circ} \mathrm{C}, 75 \pm 10 \% \mathrm{RH}$ and $801.90 \pm 10.35$ lux.

\subsection{Bioassays of starvation and wind velocity}

To test the effect of mite starvation, the wind take-off bioassay was performed using two groups of mites, one starved for $24 \mathrm{~h}$ and one not starved (i.e. fed). Five female predatory mites were used in each trial and were placed on the platform disc of coconut epidermis in the wind tunnel. After the placement of the female 
mites on the take-off platform, the vacuum pump was adjusted to the desired wind velocity, which ranged from 1 to $7 \mathrm{~m} / \mathrm{s}$. The mites were allowed 10 min to take off, after which mite dispersal was recorded. At least five different wind velocities were used, with ten independent trials for each treatment (starved and fed mites) and velocity.

\subsection{Bioassays with acaricide-contaminated surfaces}

The wind tunnel bioassays were performed as described above with the only exception that the coconut platform was contaminated with the acaricides at their respective label rates. The controls were without acaricide application (only distilled and deionized water was used). The disc fragments of coconut epidermis used as take-off platforms were immersed for $5 \mathrm{~s}$ in the desired concentration of each acaricide (or water for the control) and allowed to dry at environmental temperature before use. A minimum of five wind velocities ranging from 1 to $7 \mathrm{~m} / \mathrm{s}$ were also used in ten independent trials for each acaricide and wind velocity. Only well-fed female mites (i.e. not starved) were used in these bioassays.

\subsection{Acaricide effect on mite behaviour for wind take-off for passive dispersion}

The behaviour of female predatory mites taking off for wind dispersal was recorded at the single wind velocity of $3 \mathrm{~m} / \mathrm{s}$, because this allows dispersal with the broadest behavioural repertoire based on preliminary assessments. The wind take-off bioassays were performed as previously described, with the single difference that only one non-starved female was used per trial, which was observed throughout the bioassay using a stereomicroscope (Carl Zeiss Microscopy, Gottingen, Germany) coupled to the wind tunnel. Twenty females were used for each acaricide (and control), and the behaviours were recorded and assessed by building ethograms and analysing the first-order sequential behavioural transitions and time budgets.

\subsection{Statistical analyses}

The effects of female mite starvation and acaricide-contaminated surfaces on mite take-off for dispersal were subjected to analyses of covariance with either feeding condition (starved or not) or acaricide as the covariate and wind velocity as the independent variable (PROC GLM; SAS statistical software package; SAS Institute, Cary, NC, USA). Complementary regression analyses were also performed with wind velocity as the independent variable using the curve-fitting procedure of TableCurve 2D (Systat, San Jose, CA, USA). The significant (linear or near-linear) regression models $(P$ $<0.05$ ) were tested from the simplest to more complex models and selected based on the criteria of parsimony, high $F$-value, and steady increases in $R^{2}$ with model complexity. The residual distributions were checked in each analysis to validate parametric assumptions.

The ethograms depicting the sequence and frequency of behaviours were manually constructed for each acaricide treatment based on first-order behavioural transitions. The frequency of behavioural transitions for each acaricide treatment (in addition to the control) was tested using a $\chi^{2}$ contingency table (5 x 6; $P<0.05$; PROC FREQ in SAS). The significance of differences in the proportion of behavioural transitions between acaricide-contaminated and uncontaminated surfaces was determined using the $\chi^{2}$ test with Yates' correction for continuity ( $P$ $<0.05)$. The significance of overall treatment differences in the

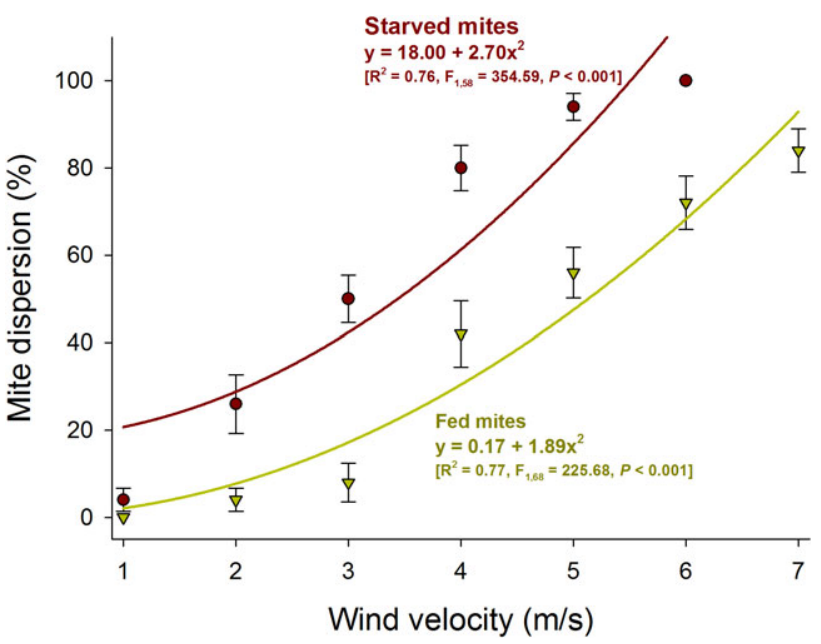

Figure 1. Dispersion (\%; mean \pm standard error) of females of the predatory mite Neoseiulus baraki, either well-fed or starved.

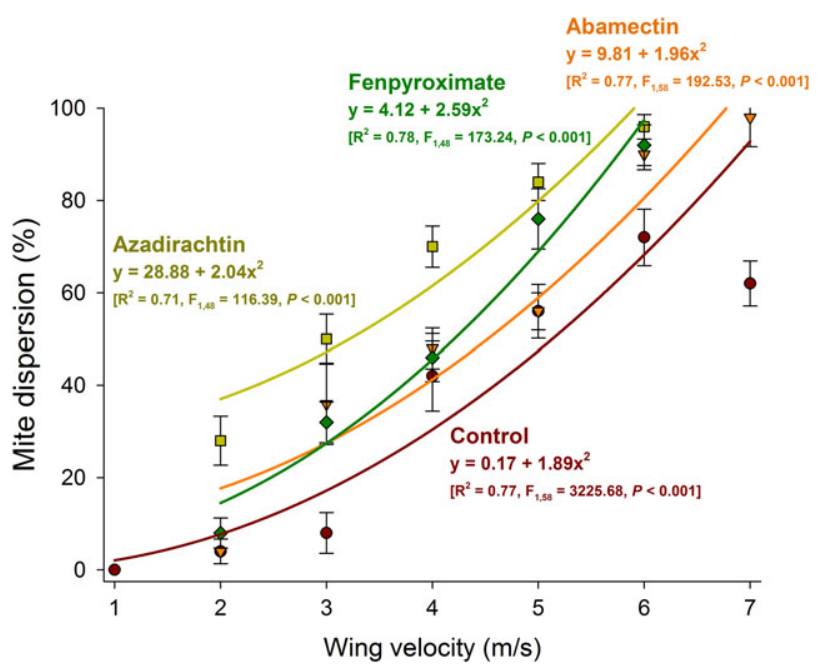

Figure 2. Dispersion (\%; mean \pm standard error) of females of the predatory mite Neoseiulus baraki exposed to acaricide-contaminated take-off surfaces.

frequency of each behavioural transition was determined using the (non-parametric) Kruskal-Wallis test $(P<0.05)$ (PROC NPAR1 WAY in SAS).

The time budget data for each behaviour regarding female mite take-off for dispersal were subjected to time failure analyses (i.e. survival analyses) using Kaplan-Meier estimators to test for overall differences with the $\chi^{2}$ log-rank test $(P<0.05)$ and to obtain the median duration of each behaviour (PROC LIFETEST in SAS). Pairwise comparisons between acaricide treatments were performed using the Holm-Sidak test $(P<0.05)$.

\section{RESULTS}

\subsection{Bioassays of starvation and wind velocity}

Analysis of covariance of mite take-off among starved and fed females at increasing wind velocities indicated significant differences $\left(F_{12,227}=58.67 ; P<0.001\right)$, with a significant interaction between starvation condition and wind velocity $\left(F_{5,117}=4.40\right.$; $P=0.001)$. Suitable quadratic regression models were subsequently obtained for starved and fed female mites, demonstrating 
(A) Control

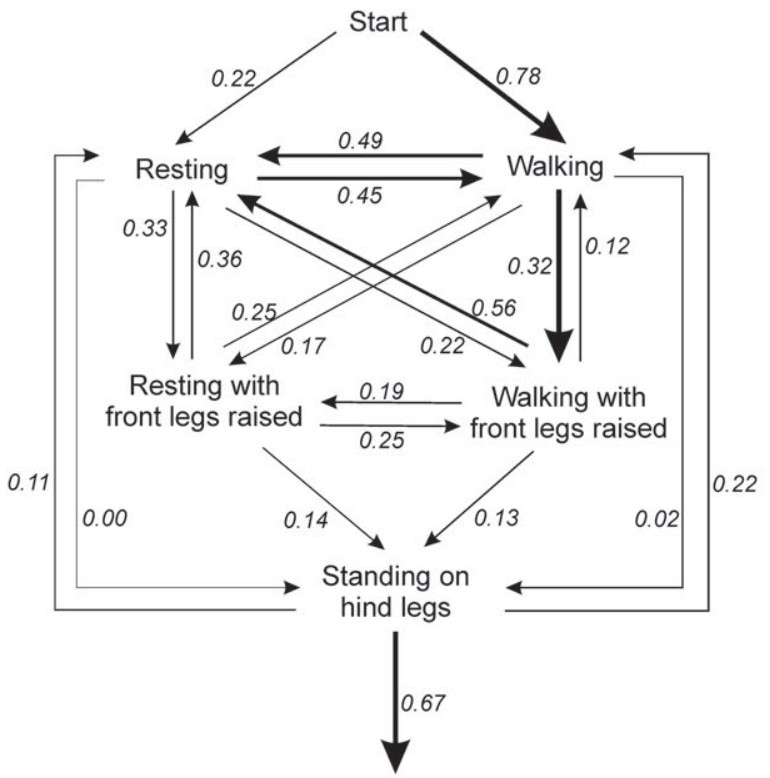

Wind take-off

(C) Azadirachtin

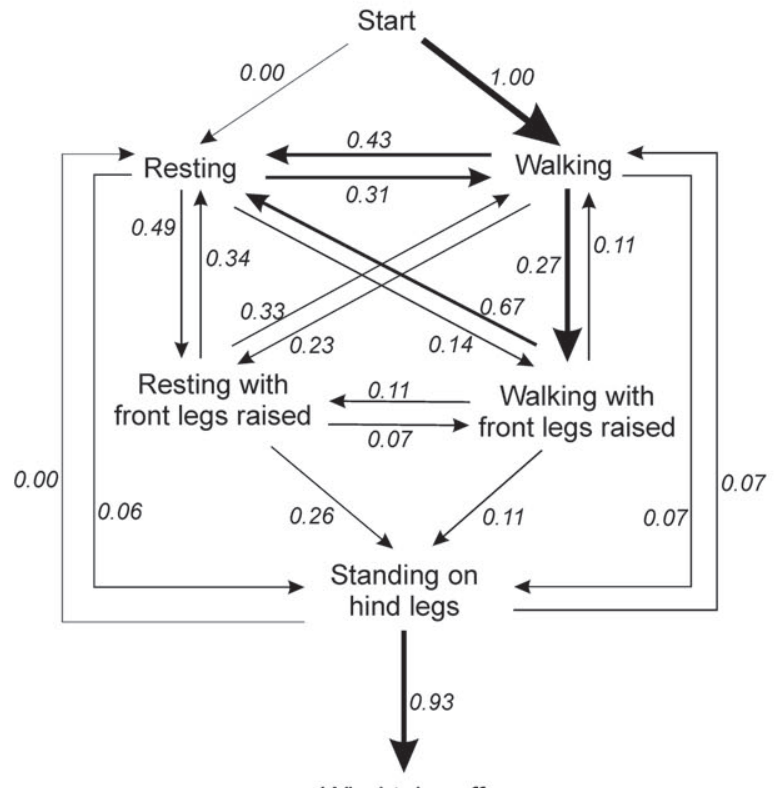

Wind take-off
(B) Abamectin

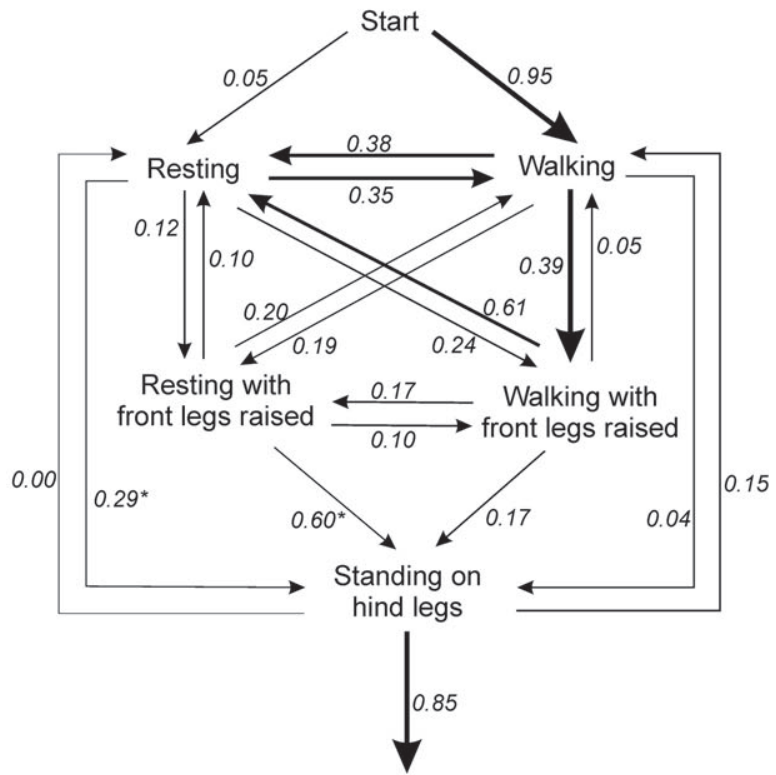

Wind take-off

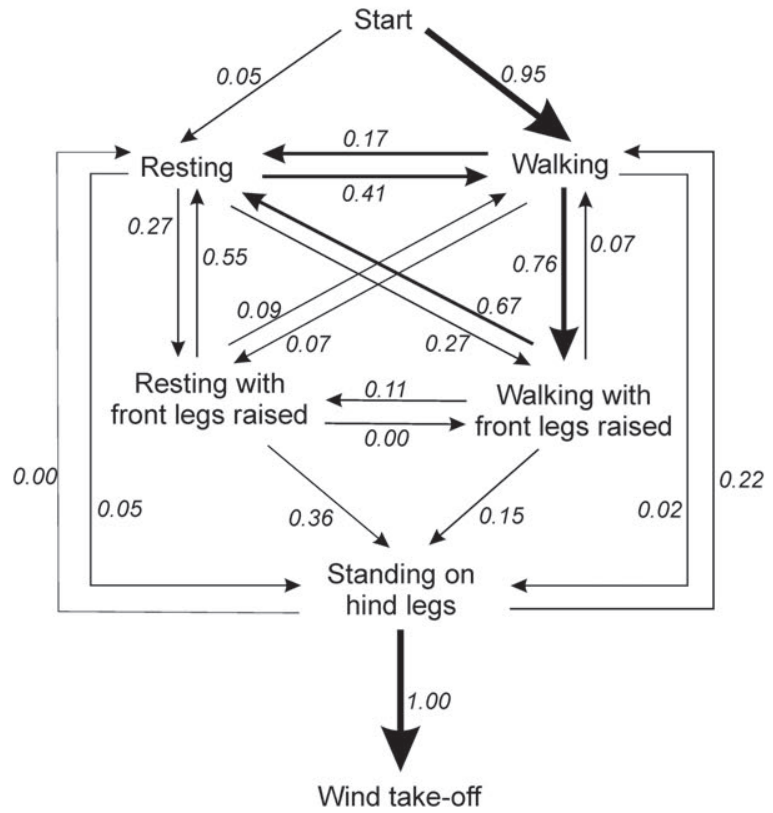

Figure 3. Ethogram of the dispersal take-off behaviours of the predatory mite Neoseiulus baraki exposed to acaricide-contaminated take-off surfaces represented as first-order transition diagrams. The solid arrows indicate each behavioural transition. The thickness of each arrow represents the frequency of each behavioural transition $(n=20)$. The asterisk indicates a significant difference in behavioural transition compared with unexposed insects on an uncontaminated surface using the $\chi^{2}$ test $(P<0.05)$.

that dispersal increased significantly with wind velocity (Fig. 1). The dispersal curve was steeper for starved mites, which always exhibited higher rates of dispersal than non-starved ones. For fed mites, dispersal was negligible at low wind speed $(1 \mathrm{~m} / \mathrm{s})$.

\subsection{Bioassays with acaricide-contaminated surface}

The analysis of covariance was significant for mite take-off from different contaminated surfaces at increasing wind velocities $\left(F_{21,198}=48.08 ; P<0.001\right)$, with a significant interaction between starvation condition and wind velocity $\left(F_{12,198}\right.$ $=1.92 ; P=0.03$ ). Quadratic models again best described the mite take-off with increasing wind velocity. The lowest rate of take-off was for untreated mites and the highest was for mites from azadirachtin-contaminated surfaces; the rate of take-off from abamectin- and fenpyroximate-contaminated surfaces was higher than that observed with unexposed insects but lower than that of azadirachtin-exposed mites (Fig. 2). 


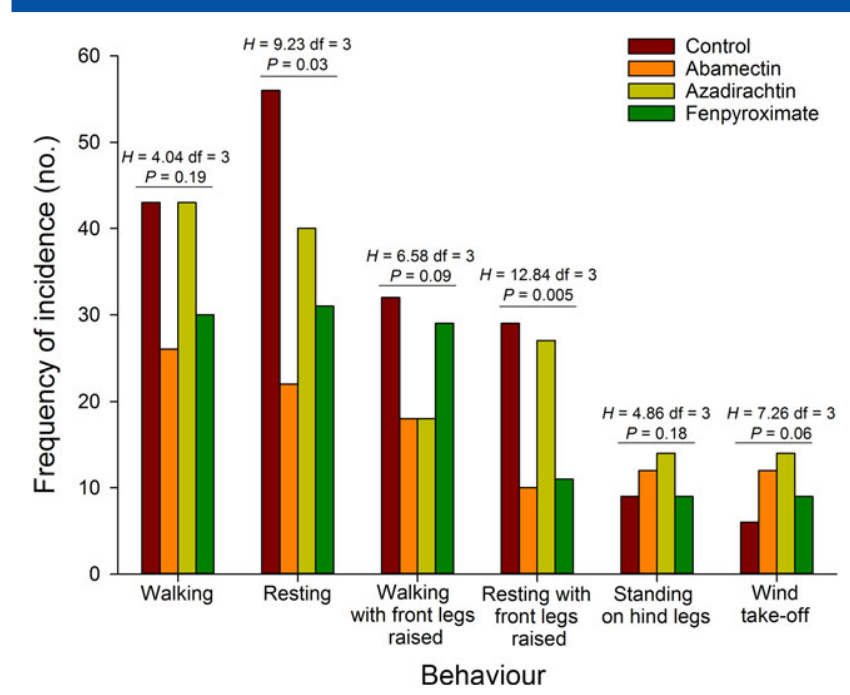

Figure 4. Frequency of the incidence of each behaviour leading to take-off for wind dispersal of females of the predatory mite Neoseiulus baraki exposed to acaricide-contaminated take-off surfaces. The results of the (non-parametric) Kruskal-Wallis test $(P<0.05)$ used to test for differences among acaricides are indicated for each behaviour.

\subsection{Acaricide effect on mite behaviour for wind take-off for passive dispersion}

\subsubsection{Sequential analyses}

The take-off for dispersal among female mites of $N$. baraki was characterized by the following sequence: resting, walking with front legs raised, resting with front legs raised, standing on hind legs, and eventual wind take-off (Fig. 3). The overall frequency of the first order of behavioural transitions for dispersal take-off from contaminated surfaces was significantly different among acaricides $\left(\chi^{2}=25.56 ; \mathrm{df}=15 ; P=0.04 ;\right.$ Fig. 4). Compared with acaricide-exposed mites, unexposed mites exhibited a higher frequency of transitions towards resting and lower latter behaviour transitions leading to take-off (Fig. 4). Some marked differences, particularly for the transition to the last behaviour before take-off, standing on hind legs, were evident between abamectin-exposed and unexposed mites (Fig. 3).

\subsubsection{Time budgets}

The length of time spent resting and walking with front legs raised did not differ among mites subjected to different acaricide-contaminated surfaces (resting: $3.77 \pm 0.43 \mathrm{~min}$ (overall mean \pm standard error); $\chi^{2}=6.30 ; \mathrm{df}=3 ; P=0.10$; walking with front legs raised: $0.85 \pm 0.14 \mathrm{~min} ; \chi^{2}=5.53 ; \mathrm{df}=3 ; P=0.14$ ), whereas the time spent in the other behaviours was significantly different $\left(\chi^{2}>9.15 ; \mathrm{df}=3 ; P=0.03\right)$. Whereas unexposed and azadirachtin-exposed mites spent more time walking and later resting with front legs raised and standing on hind legs, fenpyroximate exposure caused the opposite behaviour (Fig. 5). Mites exposed to abamectin walked less than those in the other treatments, but the other behaviours were not significantly different.

\section{DISCUSSION}

The take-off, departure or emigration stage of dispersal, unlike the vagrant and settling (or immigration) stages, is the primary organism-controlled stage of passive dispersal. ${ }^{41}$ Therefore, take-off was the target of our study exploring the potential interference of pesticides with passive dispersal, a subject

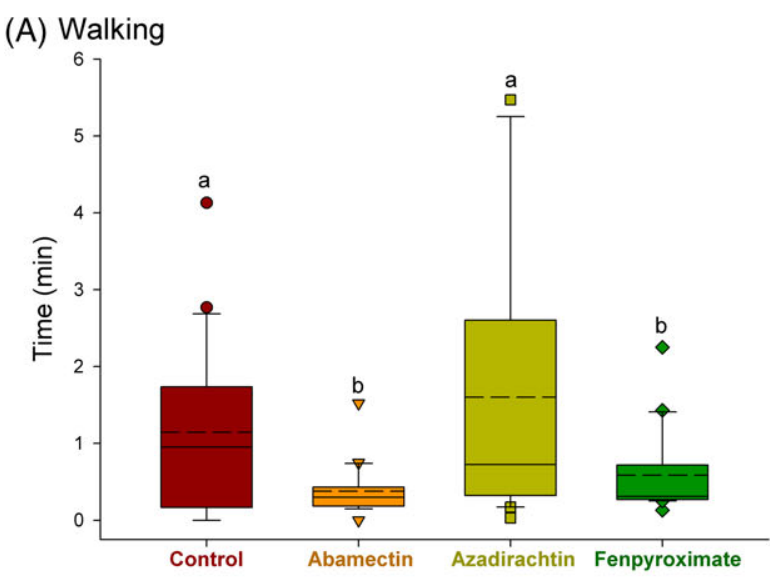

(B) Resting with front legs raised

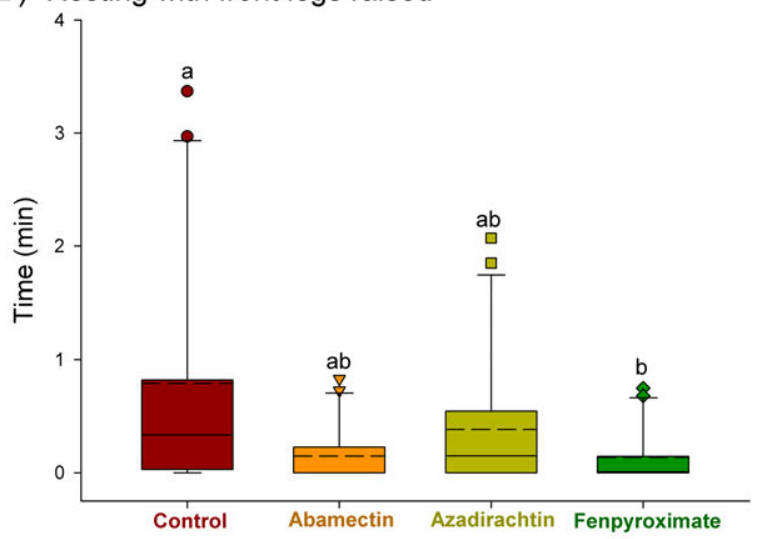

(C) Standing on hind legs

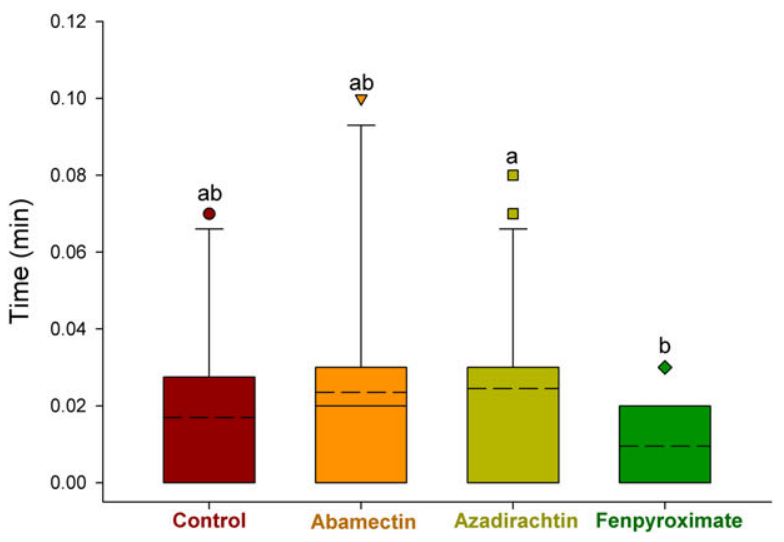

Figure 5. Duration of each behaviour leading to take-off for wind dispersal of females of the predatory mite Neoseiulus baraki exposed to acaricide-contaminated take-off surfaces. Box plots indicate the median (solid line), mean (dashed line), and dispersal (lower and upper quartiles and outliers) of the duration values. Different lowercase letters in the box plots indicate significant differences by the Holms-Sidak test $(P<0.05)$.

frequently neglected despite its potential implications for population structure and dynamics with unrecognized management consequences. In this study, the effects of food deprivation and acaricide exposure on the take-off for passive dispersal of the predatory mite $N$. baraki at different wind velocities were assessed. We hypothesized that starvation would probably favour dispersal in the search for better resource patches and that acaricides would probably interfere with such dispersal, 
either compromising take-off behaviour because of the mode of action (for abamectin and fenpyroximate) or stimulating take-off because of behavioural avoidance of the acaricide surface residue (for azadirachtin). Indeed, the results obtained with this biocontrol agent of the coconut mite indicated that starvation favoured female predatory mite dispersal and that acaricides interfered with the take-off process. However, in contrast to our initial expectation, all the compounds promoted take-off for passive dispersal as wind velocities increased.

Wind is the carrier for the passive dispersal of mites, and therefore wind velocity affects this process. In this study, increases in wind velocity between 1.0 and $7.0 \mathrm{~m} / \mathrm{s}$ led to increased rates of take-off for passive dispersal among females of the predatory phytoseiid $N$. baraki. The energetic costs involved in passive dispersal are minimal, and therefore take-off is efficient even for starved individuals. ${ }^{5,6}$ Moreover, the individual-dependent condition of starvation is more likely to favour passive dispersal because not much energy is expended in the process. ${ }^{1,4,6}$ Because the air currents (i.e. wind) are stronger in the coastal areas typical of coconut production, the importance of this relationship between wind velocity and mite dispersal is further emphasized. A positive relationship between wind velocity and (passive) dispersal has been reported for other phytoseiid predatory mites, ${ }^{41,42}$ and, as expected, N. baraki can now be added to this list.

Food limitation or unsuitability is an important proximate cause of dispersal as a condition-dependent factor associated with the decision to disperse. ${ }^{1,4,6}$ Such an association is recognized in different species, ${ }^{1}$ including species of mites and particularly predatory phytoseiids. $5,25,26,42$ Therefore, the increased rate of take-off for dispersal with food deprivation among females of the predatory phytoseiid N. baraki was not surprising. Although well-fed mites also took off for dispersal and at increasing rates with increasing wind velocities, similar to starved mites, the rate of take-off was always lower for well-fed than for starved mites. In addition to the drive of starved mites to seek better (food-rich) patches, the lower body mass is also a potential contributor that favours take-off for wind dispersal, as suggested previously by Jung and Croft. ${ }^{42}$

Sublethal pesticide exposure can interfere with individual physiology, causing changes in behaviour because of either toxic or non-toxic responses associated with such exposure. ${ }^{9,10}$ Thus, we were expecting the acaricides to interfere with passive dispersal of $N$. baraki, as the dispersal requires a particular set of behaviours leading to a posture able to maximize the effectiveness of taking off on the wind. ${ }^{12,13}$ We expected that the neurotoxic biopesticide abamectin and the electron transport inhibitor fenpyroximate would impair insect activity and compromise the behaviours leading to take-off for passive dispersal. As the primary mode of action, abamectin blocks GABA-gated receptors in inhibitory synapses, leading to paralysis, and fenpyroximate inhibits respiration, ${ }^{36-38}$ both probably affecting behaviours. However, the acaricides all stimulated dispersal take-off, the rate of which increased with wind speed, although this was our expectation only for the biopesticide azadirachtin, because this compound is known to elicit behavioural avoidance in some arthropod species, ${ }^{8,39}$ including $N$. baraki. $32,33,35$

All the acaricides tested increased the rate of take-off for wind dispersal, although the effect was strongest for azadirachtin. Thus, this botanical biopesticide apparently induced stronger avoidance in the female mites of $N$. baraki upon exposure to the contaminated surface, reflecting both the repellence and irritability caused by this compound in ambulatory studies with predatory species. ${ }^{31,33}$ Fenpyroximate exposure led to avoidance of the contaminated surface by walking $N$. baraki, but abamectin exposure did not. Thus, of these two acaricides, only fenpyroximate elicited mild irritability, and neither elicited repellence in the predatory mite. ${ }^{31}$ Based on the findings of these earlier studies and the present study, N. baraki responds differently to the three acaricides in terms of avoidance and thus take-off for dispersal, with azadirachtin causing strong repellence and irritability, fenpyroximate eliciting only irritability, and abamectin eliciting mild irritability. The use of only female mites in our dispersal take-off study might have contributed to the high resolution observed, because females are more prone to disperse and more likely to benefit from dispersal than males as founders of new colonies. ${ }^{5}$ The increased activity of acaricide-exposed mites and incidence of take-off posturing, which led to quicker take-off, favoured wind dispersal by $N$. baraki. Thus, the acaricides mediated increased take-off for passive dispersal, even for abamectin exposure, compared with unexposed mites on an uncontaminated surface.

The acaricide-induced wind dispersal of $N$. baraki was a likely response to the perception of patch unsuitability by the female mites. This response minimizes acaricide exposure and therefore will benefit the predatory mite survival when fleeing the chemical challenge. This response takes place even though the predatory mite is able to sustain the physiological cost associated with higher tolerance to acaricides compared with the coconut mite. ${ }^{34}$ This behavioural outcome and consequences have been reported in other insect species and have potential management implications. ${ }^{9,43,44}$ Although survival of the biocontrol agent will improve upon dispersal after acaricide use, the dispersal will be from a patch infested with a mite pest species that requires the predator for biocontrol. Thus, mite pest control is unlikely to benefit from such ecological selectivity achieved with dispersal, but may allow quicker recolonization and population build-up subsequently with environmental acaricide degradation. Nonetheless, this potential outcome warrants field testing to assess its likelihood and potential importance in the field.

\section{ACKNOWLEDGEMENTS}

We thank the following Brazilian agencies for their financial support: the National Council of Scientific and Technological Development (CNPq) and the CAPES Foundation (Brazilian Ministry of Education).

\section{REFERENCES}

1 Bowler DE and Benton TG, Causes and consequences of animal dispersal strategies: relating individual behavior to spatial dynamics. Biol Rev 80:205-225 (2005).

2 Ronce $\mathrm{O}$, How does it feel to be like a rolling stone? Ten questions about dispersal evolution. Annu Rev Ecol Syst 38:231-353 (2007).

3 Morales JM, Moorcrift PR, Matthiopoulos J, Frair JL, Kie JG, Powell RA et al., Building the bridge between animal movement and population dynamics. Phil Trans R Soc B 365:2289-2301 (2010).

4 Clobert J, Le Galliard J-F, Cote J, Meylan S and Massot M, Informed dispersal, heterogeneity in animal dispersal syndromes and the dynamics of spatially structured populations. Ecol Let 12:197-209 (2009).

5 Mitchell R, An analysis of dispersal in mites. Am Nat 104:425-431 (1970).

6 Bonte D, Van Dyck H, Bulock JM, Coulon A, Delgado M, Gibbs M et al., Costs of dispersal. Biol Rev 87:290-312 (2012).

7 Ghazy NA, Osakabe M, Negm MW, Schausberger P, Gotoh T and Amano $\mathrm{H}$, Phytoseiid mites under environmental stress. Biol Control 96:120-134 (2016). 
8 Cordeiro EMG, Corrêa AS and Guedes RNC, Insecticide-mediated shift in ecological dominance between two competing species of grain beetles. PLoS ONE 9: e100990 (2014).

9 Guedes RNC, Stark JD, Smagghe G and Desneux N, Pesticide-induced stress in arthropod pests of optimized integrated pest management programs. Annu Rev Entomol 62:43-62 (2016).

10 Guedes RNC, Walse SS and Throne JE, Sublethal exposure, insecticide resistance, and community stress. Cur Op Insect Sci 21:47-53 (2017).

11 Desneux N, Decourtye A and Delpuech JM, The sublethal effects of pesticides on beneficial arthropods. Annu Rev Entomol 52:81-106 (2007).

12 Shvanderov FA, The role of phoresy in the migration of eriophyid mites (Eriophyoidea). Zool Zh 54:458-461 (1975).

13 Lindquist EE and Oldfield GN, Evolution of eriophyoid mites in relation to their host plants, in Eriophyoid mites: their biology, natural enemies and control, ed. by Lindquist EE, Sabelis MW and Bruin J, Elsevier, Amsterdan, pp. 277-300 (1996).

14 Kennedy GG and Smitley DR, Dispersal, in Spider mites, their biology, natural enemies and control, ed. by Helle W and Sabelis MW, Elsevier, Amsterdan, pp. 233-242 (1986).

15 Osakabe Mh, IsobeH, Kasai A, Masuda R, Kubota S and Umeda M, Aerodynamic advantages of upside down take-off for aerial dispersal in Tetranychus spider mites. Exp Appl Acarol 44:165-183 (2008).

16 Nault LR and Styer WE, The Dispersal of Aceria tulipae and three other grass-infesting eriophyid mites in Ohio. Ann Entomol Soc Am 62:1443-1455 (1969).

17 Sabelis MW and Bruin J, Evolucionary ecology; life history patterns, food plant choice and dispersal, in Eriophyoid mites: their biology, natural enemies and control, ed. by Lindquist EE, Sabelis MW and Bruin J,Elsevier, Amsterdam, pp. 329-366 (1996).

18 Duffner K, Schruft G and Guggenheim R, Passive dispersal of the grape rust mite Calepitrimerus vitis Nalepa 1905 (Acari, Eriophyoidea) in vineyards. J Pest Sci 74:1 -6 (2001).

19 Melo JWS, Lima DB, Sabelis MW, Pallini A and Gondim Jr MCG, Behaviour of coconut mites preceding take-off to passive aerial dispersal. Exp Appl Acarol 64:429-443 (2014).

20 Johnson DT and Croft BA, Laboratory study of the dispersal behavior of Amblyseius fallacis (Acarina: Phytoseiidae). Ann Entomol Soc Am 69:1019-1023 (1976).

21 Sabelis MW and Dicke M,Long-range dispersal and searching behavior, in Spider mites. Their biology, natural enemies and control, ed. by Helle W and Sabelis MW, Elsevier, Amsterdam, pp. 141-157(1985).

22 Evans GO, Development and dispersal, in Principles of Acarology, ed. by Evans GO, C.A.B. International, Wallingford, pp.333-377 (1992).

23 Berry JS and Holtzer TO, Ambulatory dispersal behavior of Neosiulus fallacis (Acarina: Phytoseiidae) in relation to prey density and temperature. Exp Appl Acarol 8:253-274 (1990).

24 Auger $\mathrm{P}$, Tixier M-S, Kreiter S and Fauvel G, Factors affecting ambulatory dispersal in the predaceous mite Neoseiulus californicus (Acari: Phytoseiidae). Exp Appl Acarol 23:235-250 (1999).

25 Pels B and Sabelis MW, Local dynamics, over explotation and predator dispersal in an acarine predator prey system. Oikos 86:573-583 (1999).

26 Croft BA and Jung C, Phytoseiid dispersal at plant to regional levels: a review with emphasis on management of Neoseiulus fallacis in diverse agroecosystems. Exp Appl Acarol 25:763-784 (2001).

27 Moore D and Howard FW, Coconuts, in Eriophyoid mites: their biology, natural enemies and control, ed. by Lindquist EE, Sabelis MW and Bruin J, Elsevier, Amsterdam, pp. 561-570 (1996).
28 Fernando LPC, Waidyarathne KP, Perera KFG and De Silva PHPR, Evidence for suppressing coconut mite, Aceriaguerreronis by inundative release of the predatory mite, Neoseiulus baraki. Biol Control 53:208-111 (2010).

29 Melo JWS, Domingos CA, Pallini A, Oliveira JEM and Gondim Jr MGC, Removal of bunches or spikelets is not effective for the control of Aceria guerreronis. Hortscience 47:1 - 5 (2012).

30 Silva VF, França GV, Melo JWS, Guedes RNC and Gondim Jr MGC, Targeting hidden pests: acaricides against the coconut mite Aceria guerreronis. J Pest Sci 90:207-215 (2017).

31 Lima DB, Melo JWS, Guedes RNC, Siqueira HAA, Pallini A and Gondim Jr MGC, Survival and behavioural response to acaricides of the coconut mite predator Neoseiulus baraki. Exp Appl Acarol 60:381-393 (2013).

32 Lima DB, Melo JWS, Gondim Jr MGC, Guedes RNC, Oliveira JEM and Pallini A, Acaricide impaired functional predation response of the phytoseiid mite Neoseiulus baraki to the coconut mite Aceria guerreronis. Ecotoxicology 24:1124-30 (2015a).

33 Lima DB, Melo JWS, Guedes NMP, Gontijo LM, Guedes RNC and Gondim Jr MGC, Bioinsecticide-predator interactions azadirachtin behavioral an reproductive impairment of the coconut mite predator Neoseiulus baraki. Plos One 10:e0118343 (2015b).

34 Lima DB, Melo JWS, Gondim Jr MGC, Guedes RNC and Oliveira JEM, Population-level effects of abamectin, azadirachtin and fenpyroximate on the predatory mite Neoseiulus baraki. Exp Appl Acarol 70:165-177 (2016).

35 Lima DB, Oliveira HKV, Melo JWS, Gondim Jr MGC, Sabelis M, Pallini A and Janssen $A$, Predator performance is impaired by the presence of a second prey species. Bull Entomol Res 107:313-321 (2017)

36 Jansson RK and Dybes RA, Avermetins: biochemical mode of action, biological activity and agricultural importance, in Insecticides with Novel Modes of Action, Mechanism and Application, ed. by Ishaaya I and Degheele D, Springer-Verlag, New York, pp. 152-167 (1998).

37 Lümmen $\mathrm{P}$, Complex I inhibitors as insecticides and acaricides. Bioch Bioph Acta 1364:287-296 (1998).

38 Dekeyser MA, Acaricide mode of action. Pest Manag Sci 61:103-110 (2005).

39 Mordue AJ, Morgan ED and Nisbet AJ, Azadirachtin, a natural product in insect control, in Insect Control: Biological and Synthetic Agents, ed. by Gilbert $\mathrm{LI}$ and Gill SS,Elsevier/Academic, London, pp. 185-203 (2010).

40 Agrofit, Sistema de agrotóxicos fitossanitário do Ministério a Agricultura, Pecuária e Abastecimento. [Online]. Available: http://extranet .agricultura.gov.br/agrofit_cons/principal_agrofit_cons. [6 February 2017].

41 Sabelis MW and Afman BP, Synomone-induced suppression of take-off in the phytoseiid mite Phytoseiulus persimilis Athias-Henriot. Exp Appl Acarol 18:711-721(1994).

42 Jung $C$ and Croft BA, Ambulatory and aerial dispersal among specialist and generalist predatory mites (Acari: Phytoseiidae). Environ Entomol 30:1112-1118 (2001).

43 Braga LS, Corrêa AS, Pereira EJG and Guedes RNC, Face or flee? Fenitrothion resistance and behavioral response in populations of the maize weevil. J Stored Prod Res 47:161 - 167 (2011).

44 Guedes NMP, Guedes RNC, Ferreira GH and Silva LB, Flight take-off and walking behavior of insecticide-susceptible and resistant strains of Sitophilus zeamais exposed to deltamethrin. Bul Entomol Res 99:393-400 (2009). 